\title{
CICADAS IN TEXAS
}

East central Texas is a veritable cicada paradise. I have never visited a region where so many species are as abundant as occur in, for instance, the Madison County region. They are numerous in many parts of the post oak woods, but are most plentiful in the alluvial forests and groves in the lower grounds along the Navasota and Trinity Rivers. Here in June and July, the air is vibrant with the songs of Tibicen superba, T. pruinosa, T. resh, T. marginalis, T. chloromera, T. lyricen and Diceroprocta vitripennis. The chorus becomes most intense late in the afternoon, when pruinosa may predominate. The songs of the species mentioned differ considerably and are quite easily recognizable. Tibicen resh is often found in great numbers in some large detached oak or other tree standing in the open, the trunk of which may bear scores of the cast skins of this species. Resh may be silent for long intervals, when suddenly the whole population may burst into song simultaneously, resulting in an ear-splitting din which subsides as suddenly as it arose. The great cicada-killing wasp (Sphecius speciosus) is a constant attendant of the cicada aggregations, its deep hum being audible among the branches where an occasional agonized shriek of an unfortunate victim reveals the success of the wasp's hunting. These wasps vary greatly in size, and I have seen the smaller individuals (25-35 $\mathrm{mm}$. in length) capturing the smaller cicadas as Diceroprocta vitripennis. Undoubtedly the larger individuals (40-50 $\mathrm{mm}$. in length) select the larger species as resh or marginalis. Lurking in openings in the forests may be seen individuals of the robber-fly, Microstylum morosum, the largest American Asilid, sometimes reaching a length of $50 \mathrm{~mm}$. This species frequently pounces on cicadas, carrying them off in its long legs to a bush or branch. Here the fly, suspended from the twig by a front leg and pressing the cicada to its long sharp beak with the others, feeds on its victim. I have seen this fly seize $D$. vitripennis, and $\mathrm{Mr}$. F. F. Bibby and Mr. W. C. O'Dowd once took a large T. resh which had been captured by this Microstylum.

StANLEY W. BROMLeY. 

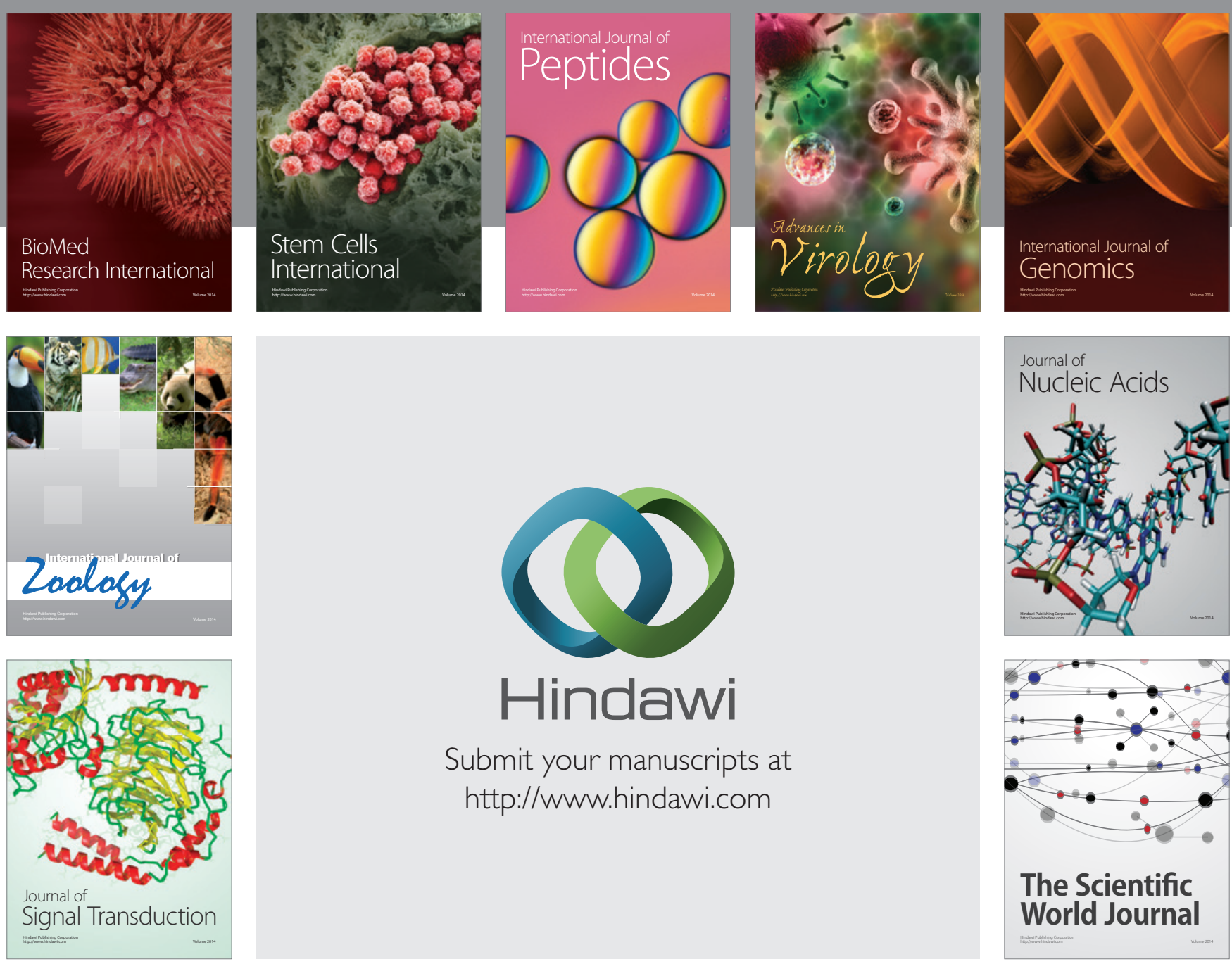

Submit your manuscripts at

http://www.hindawi.com
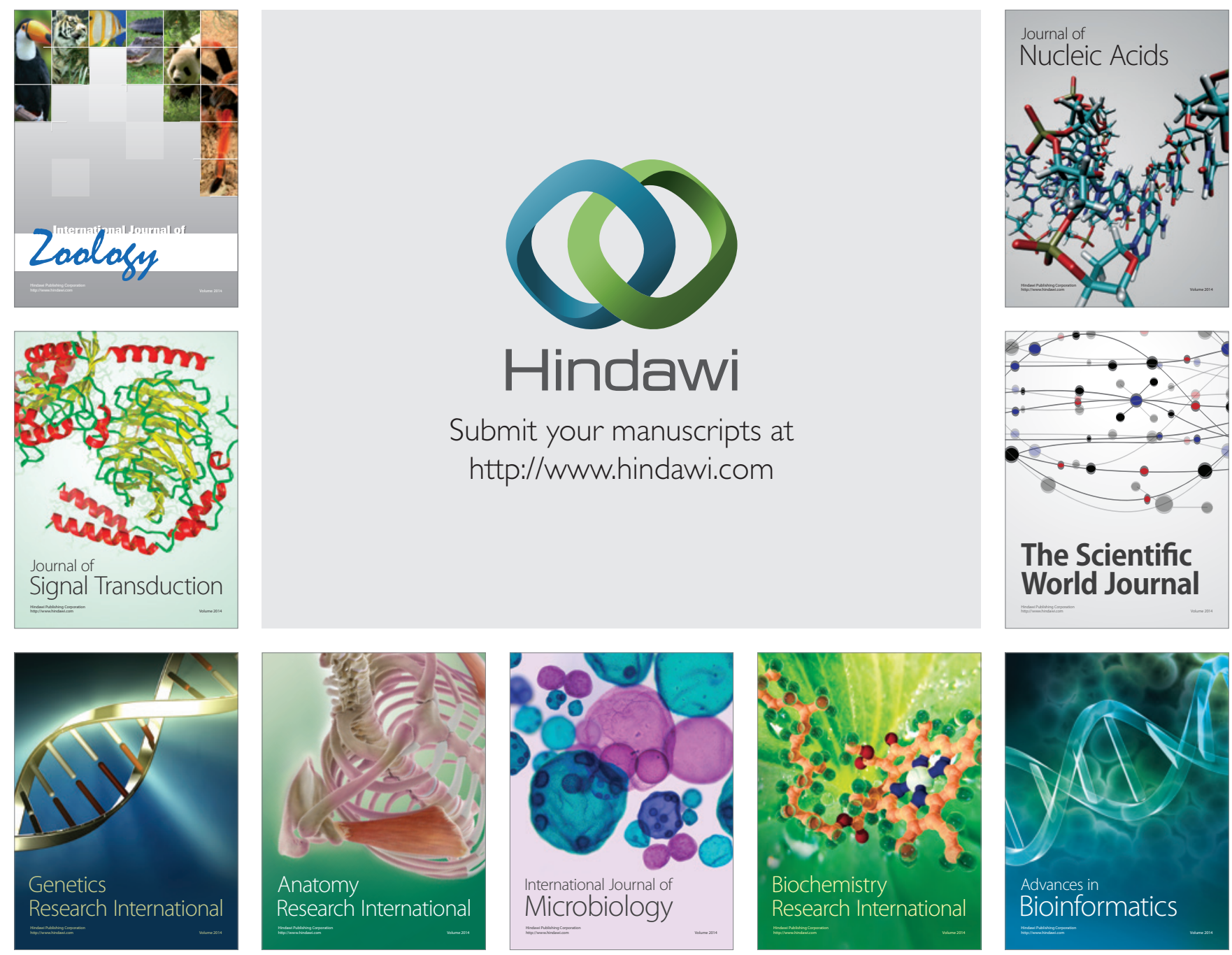

The Scientific World Journal
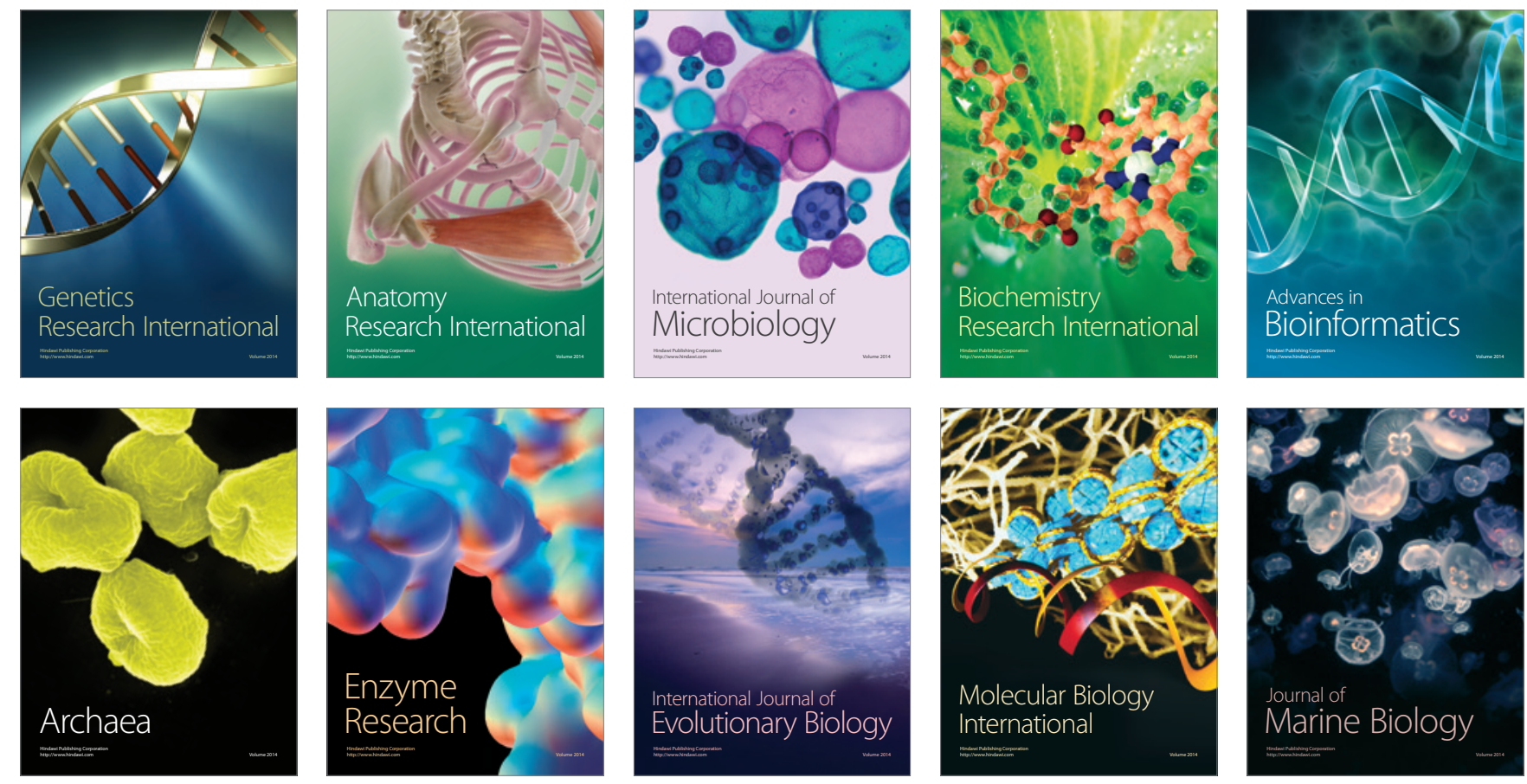